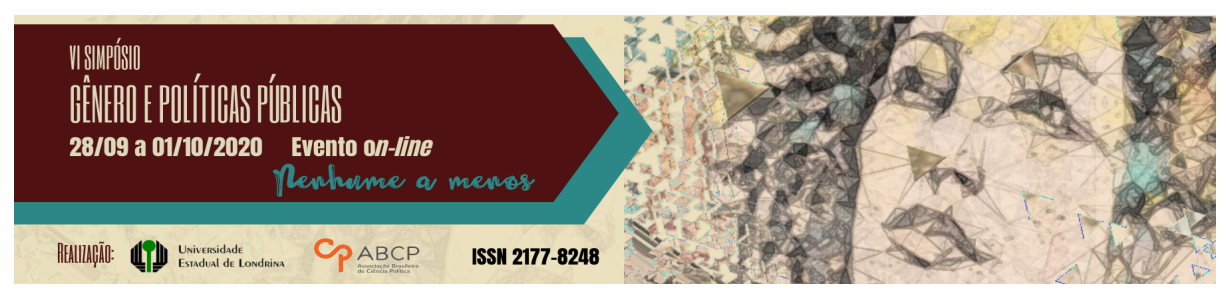

\title{
Coisas quebradas: afetividades desviantes
}

\author{
Ludmila Castanheira1; ${ }^{1}$ Lua Lamberti de Abreu²
}

\section{Resumo}

A performance de feminilidade em nós está "quebrada". Nós somos mulheres: uma cis, lésbica outra trans, com afetividades circunstanciais. Para o olhar normativo, nos falta ou sobra algo. Não correspondemos ao binarismo de gênero. Nós estamos entre. E não há espaço para o que não se deixa catalogar imediatamente. Se as impressões sobre nós não são precisas, nós, automaticamente, somos retiradas da categoria humana. Nos tornamos coisas e, como tal, não merecemos qualquer deferência. As "coisas" devem ser eliminadas do mundo maniqueísta no qual nenhuma dúvida é bem-vinda. Somente por existir, nós ameaçamos os frágeis castelos de areia da normatividade. A partir dessa perspectiva, de existências que perturbam o estabelecido, temos sido mortas, fetichizadas, silenciadas. Não somos casal, nem família. Bando, talvez. Nós nos queremos assim, quebradas, olhando para as feridas uma da outra, e debochando da obviedade da vida circunscrita pela norma.

Palavras-chave: dissidência; lesbianidade; travesti.

\begin{abstract}
The femininity performances in both of us is "broken". We are women, a cisgender and lesbian and a transgender of circumstantial affections. At the normative eye, we either miss or overflow something. We don't correspond to gender binary rules. We are between. There's no space to whatever refuses to

1 Doutora em Artes da Cena pela UNICAMP, professora no curso de Artes Cênicas -
Licenciatura em Teatro na UEM. E-mail: ludmilacastanheira@gmail.com
2 Lua Lamberti de Abreu, graduada em Artes Cênicas - licenciatura em Teatro (2016) e
Mestra em Educação (2019) ambos pela UEM, artista transformista e transativista. E-
mail: luax.l.de.a@gmail.com
\end{abstract}

GT 16 - LGBTQ+fobias e educação: estratificações, resistências e transgressões 
be cataloged right away. If our impressons aren't precise, we, automatically are removed from the human category. We become things and, as such, we don't deserve any deference. "Things" should be eliminated from the manichaen world in which none of us are welcome. Only by existing, we threaten the fragile sandcastles of the normativity. From this perspective, of existences tha disturb what has been settled, we have been killed, fetishized, muted. We are not a couple, neither a family. A flock, maybe. We want ourselves like this, broken, looking to eachother wounds, mocking of the obviousness of a life that has been circumscribed by the norm.

Keywords: dissent; lesbian; transvestite

\section{É preciso destruir o amor}

Durante o período de quarentena, variável no território nacional, mas estabelecido aqui a partir de março, muitas artistas, pensadoras, figuras públicas e influencers se fizeram presentes com lives, eventos virtuais, mostras e debates on-line e produções de conteúdos variados para as plataformas digitais, visando o público em isolamento social. Entre elas, apesar de muitas e tantas, nos interessa especialmente uma live, da artista multilinguagem travesti preta Linn da Quebrada, Lina Pereira, com a Drag Queen preta Bianca DellaFancy, Fellipe da Silva Souza. Não é a primeira vez que a travesti fala publicamente sobre questões de afeto, amor e relacionamentos, mas nessa live específica, ela usa fala sobre a necessidade de "destruir o amor".

A justificativa para esta requisição, para a artista, é que a noção de amor só existe para aquele suposto indivíduo neutro, que notadamente é um homem, branco, cisgênero, hétero, jovem, magro, classe média-alta, cristão, eurocêntrico e, e, e. Ou seja, ao sujeito não marcado. Para todas as outras pessoas, esse amor é uma idealização romântica de filmes hollywoodianos, livros aburguesados, animações colonizadoras... Em suma, não existe para as abjeções. E para nos mantermos no reino do felizes para sempre, convidamos você a um exercício simples: cite um filme da Disney em que o/a/e vilã/o/e termina casado/a/e, feliz ou em paz? E como são essas personagens? 
No imaginário social, a vilania é delineada como o lugar da abjeção: seja por bombardeio de referências midiáticas, currículos escolares e ocultos, pedagogias coercitivas dentro e fora de escolas, dogmas religiosos, moral e bons costumes coloniais. $\mathrm{O}$ corpo gordo, $\mathrm{o}$ corpo racializado, de gênero não conforme, de sexualidade dúbia ou não heterocentrada é sempre ridículo, desprezível, o que deve ser exterminado para que o final feliz aconteça. A fórmula de casal, de amor e de finais felizes só pode existir a partir do apagamento e, muitas vezes, do assassinato das dissidências. A norma casa-se "para sempre" com a norma e produzirá sempre descendências normais.

De volta à mencionada live, quando Linn frisa que precisamos destruir o amor, é desse amor normativo que ela está tratando. Não da ideia abstrata de amor enquanto um sentimento amplo que abarca afetos, sexos, carinhos, intimidades e até mesmo o básico do respeito aquele amor entre amigues, familiares, comunidades. Esse amor dissidente, ainda assim, corre o risco de ser cooptado pelos mesmos modos de operação que instituem o amor romântico. Também ele está sujeito a ser perpassado por noções embranquecedoras, alienadoras, heteronormativas, cisgnerificantes etc.

Afeto, para uma pessoa trans, é tanto quanto não pode caber num único texto. Mas neste aqui, interessa olhar para os afetos relacionais ou afetivo-sexuais. Ainda nesta live, Lina Pereira confessa estar exausta de ter somente o campo sexual, vazio de afeto, vazio de empatia, vazio de cuidado e respeito, mas continuar neste exercício ali porque o toque é o momento em que sua existência é humanizada. Essa noção de humanização vem tentando tapar o buraco identitário que a cisnorma branca tenta criar no tecido social: a noção de que "somos todes humanes" e, portanto, iguais, de modo que problemas advindos de noções como raça, gênero, classe, sexualidade seriam irreais, irrelevantes e pontuais - o que não só não é uma verdade como perpetua a comodidade da norma em manter-se alienada em suas prerrogativas de universalidade.

A fala de Linn evidencia, ainda, a satisfação de ser validada a 
partir do pertencimento ao círculo mágico da norma. Ao ser circunscrita enquanto possível, eleita como um corpo desejável mesmo que para uma trepada rápida e escondida no banheiro - por um homem cis, a corpa travesti passa a existir.

Este panorama evoca uma metáfora imagética, mais ou menos nos seguintes termos: na mesa do banquete, oferecida pelo senhor aos seus iguais, a mulheridade cisgênera só é bem vinda se trouxer os pratos da cozinha, como a negritude só é tolerada se estiver ali para servir. As transgeneridades e as sexualidades não héterocentradas não são sequer convidadas. A estas existências "quebradas" ficam destinadas as sobras, a comida fria depois de a louça lavada. Para quem nunca viu um pão, a casca seca faz-se um banquete. Não somente pela saciedade da fome, mas pelas migalhas da atenção. Esta, posta no preparo do alimento destinado a uma visita ilustre, mas que, por descuido e nunca por intenção, respinga em quem fica com o que restou.

Neste cenário nós temos estado sempre atrás das portas, nos fundos, embaixo da mesa. Mas estes também são lugares estratégicos, a partir dos quais podemos puxar a toalha e mandar à merda as regras de aceitação: deixar de nos importar com a aprovação da norma, e assumir o lugar de não pertencimento. Depois de cagar no prato do senhor, vamos nós, as esquisitas, para um boteco qualquer. Nesse sentido, destruir o amor é usar, nas palavras de Ventura Profana, "bota de python para pisar na cabeça do senhor".

Há também um destaque importantíssimo a ser feito nesse cenário: os afetos são políticos. A quem se endereçam, como se validam e mesmo a noção de monogamia também está inserida nesse dispositivo da sexualidade, que pressupõe a servidão feminina. A monogamia é uma regra que sacramenta a família e que deve ser seguida sem desvios, exceto pelos homens cisgênero, estes reféns dos instintos, incapazes de contê-los e que depreendem a compreensão ilimitada das mulheres com quem se relacionam. 
A heterossexualidade é uma instituição política que retira o poder das mulheres. O reforço da heterossexualidade e, mais ainda, da heterossexualidade monogâmica para mulheres é um meio de garantir aos homens cis hétero o acesso físico, econômico e social a elas. Nesta equação está subtraída a possibilidade lésbica, delineada como um panorama habitado por pobres mulheres frustradas que, incapazes de manter relações com homens, resignaram-se às relações com seres inferiores, da mesma estirpe que elas: outras mulheres. Porque, obviamente, a fragilidade masculina colapsaria se ousasse imaginar que as lesbiandades não se dão pela falta, nem pelo lamento, mas pela celebração erótica e afetiva cuja existência autônoma independe do que querem ou pensam os homens cis hétero.

As lesbianidades são uma potência política, no sentido de que também elas, como convida Linn, desmontam a ideologia do romance heterossexual, imposta a nós desde a infância a partir dos contos de fada, do cinema, da propaganda, das canções "de amor", das datas comemorativas. A doutrinação prematura das mulheres para o amor romântico prevê que as necessidades masculinas devem ser postas em primeiro lugar, e que a pulsão sexual masculina é incontrolável, e deve ser satisfeita sob qualquer hipótese, incluindo-se a despeito de nossa autonomia sobre nossos corpos. Desobedecer a este acordo social tácito, necessariamente, abala os lugares comuns que sustentam a norma.

Em graus diferentes, todas as mulheres são vítimas na heterossexualidade compulsória. Mesmo nós, coisas quebradas, cuja performance de gênero não permite repousar nas gavetas tranquilas da binaridade. Se não somos lidas como "femininas", as lésbicas temos reiteradamente sido alocadas numa espécie de "caminho de bumerangue" em que nem nos livramos de fato da feminilidade, nem alcançamos por completo a masculinidade. Somos, por fim, segundo a métrica da normatividade, antes e sempre, impostoras.

Não ocorre à organização social que segura esta régua de medir adequação que as lésbicas não almejamos a masculinidade mais do que debochamos dela. Assim também temos jogado com os aspectos 
considerados femininos. Nós, de maneira consciente ou não, temos tratado estas segmentações como tecnologias de gênero a serem reapropriadas, negociadas e pirateadas. Temos dobrado, inclusive, as noções de femme e butch e nos permitido oscilar entre estes papéis, inventar outros e desobedecer a todos eles. Sobretudo, temos reivindicado que nossa sexualidade se defina pela atração por mulheres. Não pelo desprezo aos homens cis hétero. Porque nossa sexualidade é sobre nós, não sobre eles.

A possibilidade de haver no mundo qualquer coisa que não se destine à satisfação cismasculina ainda é mais chocante do que deveria. Especialmente numa organização patriarcal em que temos ocupado o lugar de dote - a objetificação em forma de prêmio. Nessa lógica, em que temos sido separadas em categorias cujas variações redundam em puta ou santa, com as quais os homens de bem se casam ou se divertem, é espantoso que dediquemos afeto entre nós. Para manter a metáfora romântica perpetrada pelas "histórias de amor", é como se a princesa jogasse o sapatinho perdido no príncipe para se casar com a bruxa.

\section{O amor na dissidência}

É possível notar nas falas de tantas corpas dissidentes que, mais e mais, temos feito o movimento de nos fecharmos em nossas comunidades. Esse movimento se dá em diversas escalas, assim como com casais afrocentrados, transcentrados, etc. Os motivos para esse centramento é a noção de que nossas existências não podem depender das regras de normalidade, até porque não se pode ganhar um jogo cujas regras são inventadas pelo adversário - para serem cumpridas por nós e desrespeitadas por ele.

Quando Linn nos chama a destruir o amor, está atentando contra o amor que estabelece famílias consanguíneas em que o bemestar do macho figura como princípio inquestionável. $\mathrm{O}$ amor estabelecido como esse que sufoca aquelas, aqueles e aquelus que não 
são conformes. Destruir o amor neste caso nada tem a ver com espalhar (mais) amargura e dor nas relações já tão adoecidas e nos resignar a descrever a distopia. Não. Trata-se de desviar menos que enfrentar o horror do nosso tempo e inventar o amor na dissidência.

A questão é que nosso campo de afetação, nossos desejos e nossa libido também são atrelados ao meio social e às construções culturais que elegem o belo enquanto norma. Ou seja: sugerem e/ou impulsionam nosso imaginário para aquela única possibilidade, de aceitável, de amável. Para quem não cabe nessa fórmula, resta o desespero. E nem só de identidades marginalizadas se compõe o muro das lamentações das desesperadas, porque mesmo a identidade cisbranca-hétero pode ser ceifada desse plano de final feliz se porventura deslizar em cumprir qualquer uma das obrigações normativas. A norma só se sustenta enquanto materialidade a partir das performances e dos discursos que circundam, erigem e validam determinadas noções, convidando corpos a perpetuarem fórmulas coercitivas.

O amor na dissidência está cansado da repetição ad nauseum dos retratos brancos, cisgêneros e heterossexuais nos seus finais felizes das telenovelas, filmes e séries. $\mathrm{O}$ amor na dissidência não perdoa a "inocência" dos livros didáticos em não trazer corpos gordos, trans e racializados para ilustrar a humanidade. $\mathrm{O}$ amor na dissidência quer vomitar no fato de que as pessoas famosas sejam embranquecidas, passáveis, além de ricas.

Nós desistimos de nos querermos apenas romanticamente e nos abraçamos enquanto quebradas, puídas, rotas. Balançamos bases éticas e estruturantes de uma sociedade intolerante e buscamos outras geografias para os mapas dos afetos. Faz parte desse tráfego esquecermos masculinidades cisgêneras brancas no curso de nossas rotas afetivas. Não por retaliação e exclusão. Mas pelo entendimento de que os desejos têm sido direcionados a alguns corpos mais que a outros, alguns corpos têm importado, outros não, algumas vidas têm figurado como preserváveis, outras como descartáveis. 
Como houvesse alguma reparação possível, reiteramos a proposta de Linn da Quebrada e a complementamos com a de um continuum lésbico, capaz de abarcar um grande escopo de variedades de experiências de identificação entre mulheres. A dissidência amorosa entre a travesti e a sapatão que escrevem esse texto é atravessada pelas experiências de identificação entre nós e não se restringe ao erotismo do qual nossa amizade está - sim, também, mas não só - impregnada. Mas, sobretudo, nosso continuum lésbico é um vínculo contra a tirania masculina. Ele é o meio pelo qual damos e recebemos apoio prático e político.

É pelo continuum lésbico que exercitamos o desejo não confinado a qualquer parte do corpo em si mesmo, mas como uma energia difusa e onipresente de compartilhamento da alegria. A partir dele, nos tornamos menos propensas a aceitar a resignação, a autonegação, a vida minguada e a tristeza que determinaram para nós, se fracassamos no amor romântico. Nós nos movemos circunstancialmente para dentro e para fora desse continuum, mesmo que não haja entre nós uma relação lésbica.

A afetividade entre nós, coisas quebradas, nada deve ao amor romântico. Nós longe das bases da cishetronormatividade, não estamos preocupadas em saber com quem cada uma de nós dorme, não cobramos exclusividade, não buscamos as sanções no Estado e da Igreja para a nossa união. Nós não nos vigiamos para o cumprimento dos papéis de gênero, e temos nos agrupado em bandos, mais do que em famílias.

Nossa intimidade não está a serviço da norma, mas ajuda a nos reconhecermos e aceitarmos em nossas coisificações. Porque o modelo de humanidade não nos inclui, nem tem funcionado de forma que nos contemple. Da mesma forma, o "bom funcionamento" assíduo, produtivo e rentável, que adoece pessoas em nome da máquina capital, nos percebe como defeituosas. Também a isso celebramos. Sem a ingenuidade de escapar, mas justamente habitando a grande engrenagem de produção e consumo aos trancos, sazonalmente, 
quebradas. Por derrisão, nos apresentamos assim: coisas quebradas. 